\title{
The Design Flow and Feasible Construction Sets of Project Transaction Mode
}

\author{
Meng Yao \\ School of Environment and Civil Engineering, Jiangnan \\ University \\ Wuxi China \\ 945718713@qq.com
}

\author{
Liu Xun \\ School of Environment and Civil Engineering, Jiangnan \\ University \\ Wuxi China \\ Liuxun8127@163.com
}

\begin{abstract}
The project transaction modes have a profound impact on the project schedule, quality and investment objectives. In this paper, the design flow of the project transaction mode is presented according to the general principles of engineering design. Besides, the key issues involved in the design process are analyzed on the basis of the design flow. Then, the selection process of project delivery methods, contract types and owner's management are furtherly discussed, which have provided a formalized and quantitative analysis process for the owner's design of construction projects trading patterns. The engineering example of a water diversion project shows that the design flow of project transaction mode is feasible by further comparison, analysis and screening for project delivery methods, contract types and owner's management. The design flow and feasible set can reduce the number of possible options for project transaction mode and reach the purpose of reducing the difficulty for the owner's final decision.
\end{abstract}

Keywords- Project Management; Construction Project; Project Transaction Mode; Design Flow; Feasible Set

\section{INTRODUCTION}

The project transaction mode regulates the project delivery scope, each participant's responsibility, owner's payment methods and distribution of project risks among each participant. At the same time, it also provides a frame for the implementation of construction project. The project transaction determines the construction schedule, cost, quality and contract management of the project on a large scale, which means that choosing or designing a proper transaction mode is a vital factor for the success of a project ${ }^{[1-3]}$. Owner's management, delivery method and contract type are included in the project transaction mode and different combinations make up different transaction modes $^{[4]}$

Many scholars have researched the owner's management, delivery method and contract type. Reference [5] studied the classic owner's management style, that is supervision and project management (PM) by using transaction cost economics. The result shows that it is suitable to use PM when the owner is weak in management or lacks experience, while on the contrary it would be more reasonable to use supervision. Reference [6] compared with many kinds of delivery method from the aspect of cost, schedule and quality including DesignBid-Build (DBB), Design-Build (DB) and so on, which concluded that DB had advantage in cost and schedule and the project using DB was not at a disadvantage in quality management. Reference [7-9] discussed the applicable conditions of each delivery method and explored the impact to the project performance brought by different delivery methods. It finally proposed to choose the delivery method according to the experts' experience. Reference [10] classified the construction project contract into lump sum contract, cost-plus contract, and cost reimbursable contract. Reference [11] pointed out that the contract types should fit with the features of projects and stressed that the risk distribution in the contract would directly influence the project cost. Reference [12] put forward a view that the design of transaction mode included organization design and contract design. Reference [13] claimed how to choose project contract from the aspect of transaction cost and pointed out that the ultimate goal of choosing a contract was to minimize the producing cost and transaction cost. Reference [14] studied the design of project delivery method in the concept of innovative project delivery method. Reference [15] put forward the design frame and steps based on the transaction cost of construction project. Reference [16-17] considered that transaction mode was a process of designing and building a project for the owner, it changed with the contract types and technology relationship of different participants.

According to the researches above, researchers could find that: (1) There have already existed classic delivery method, owner's management and contract types in engineering practice. The common concept is to choose from the existing classic styles or methods; (2) Few researches design the transaction mode from the whole system, which not only goes against to the development of transaction mode but also couldn't meet the need of construction project. As a matter of fact, on the one hand most of the classic transaction modes came into being under certain circumstances. With the development of economy and technology, the project and construction conditions changed. Therefore, researchers need to innovate the classic modes. On the other hand different construction projects ranges from the project itself and construction condition so it is obvious that the existing modes is hard to satisfy the differences between projects. Researchers need to design the transaction mode according to the features of a project. Based on what researchers have mentioned above, according to the general principles of engineering design, this paper mainly studied the establishment process of a construction transaction mode and the selection process of delivery method, contract type and owner's management. 


\section{THE DECISION-MAKING IN CONSTRUCTION TRANSACTION MODES}

The construction project transaction has been involved in all the producing process. What is more, the construction project has large project quantity, complicated structures, high-standard quality, long periods of constructing and huge money investments, which makes its transaction much different from the usual goods. In order to raise the success possibility of construction transaction, people have summarized many sorts of formal or informal modes to regulate the construction trade, such as construction project transaction mode, delivery methods and different contract sorts. The formation and development of every formal or informal modes are to adapt to the special needs of some projects. When it comes to a specific construction projects, the owner should select a proper transaction mode based on its specific situations so as to promote the project to go smoothly. Hence, there are many decisions for the owner to make in the transaction. The followings are particularly important:

(1)The decision-making in delivery methods. The delivery methods usually have an obvious impact on the contract price and transaction cost. The DBB can promote competition and thus reducing the contract price, while on the other hand it increases the owner's management cost. On the contrary the DB/EPC may lower the competition extent which may not be helpful to reducing the contract price but the management cost of the owner will decline. To sum up the owner should consider comprehensively when selecting delivery methods.

(2) The decision-making in contract types. The contract type determines how to settle the contract price and the distribution of project risks between the owner and the contractor. Distributing the risks properly will increase the transaction efficiency and guarantee the project going on smoothly. Thus selecting the contract type is one of the owner's important decisions.

(3) The decision-making in owner's management. Different management styles have different cost and effects. Self-management can satisfy the requirements on the maximum extent but usually companied with a large organization and high management cost. Commissionedmanagement will raise the management standard and simplify the organization but the owner may have less control on the construction process. Therefore the owner's management should be determined by the management ability and the features of the project.

(4) The decision-making in the general transaction mode. The construction project transaction is made up of three parts that is delivery methods, contact type and owner's management. According to the system engineering theory, the local optimum of the three parts can't equal to the global optimum. Thus researchers can establish a feasible set by combining the three parts and choose the best transaction mode from it by using compatibility analysis.

\section{COMBINATION AND COMPATIBILITY ANALYSIS OF TRANSACTION MODES}

\section{A. The combination of delivery methods, contract types and owner's management}

When there are $\mathrm{m}$ kinds of delivery method, $\mathrm{n}$ kinds of owner's management and $\mathrm{k}$ kinds of contract types, the feasible project transaction mode is $S=m \times n \times k$ and $\mathrm{s}$ stands for the number of feasible modes in the set. For example, when $\mathrm{m}=3, \mathrm{n}=3, \mathrm{k}=2, \mathrm{~s}=18$. Therefore researchers can select a better mode by comparing and analyzing the 18 modes. Actually researchers could use compatibility analysis first to screen out some modes.

\section{B. The compatibility analysis of delivery methods, contract types and owner's management}

The delivery method and owner's management are closely related while the contract type is rather separated from them. Hence there may be compatible problems between the delivery method and the owner's management. For example, it is incompatible to combine the $\mathrm{CM}$ at risk delivery method with the $\mathrm{CM}$ agency owner's management, because when taking CM at risk as delivery method, the owner and the CM Company sign a contract. While taking CM agency as the owner's management, the owner and the CM Company sign a consulting service contract. It is impossible for the owner to sign a contract and a consulting service contract with one company at the same time. Therefore researchers establish Table 1 to make compatibility analysis between the delivery method and the owner's management.

Table 1 the combination of delivery method and owner's management

\begin{tabular}{|l|c|c|c|}
\hline & management $_{1}$ & management $_{2}$ & management $_{m}$ \\
\hline method $_{1}$ & Mode $_{11}$ & Mode $_{12}$ & Mode $_{1 m}$ \\
\hline method $_{2}$ & Mode $_{21}$ & Mode $_{22}$ & Mode $_{2 m}$ \\
\hline method $_{3}$ & Mode $_{31}$ & Mode $_{32}$ & Mode $_{3 m}$ \\
\hline method $_{n}$ & Mode $_{n 1}$ & Mode $_{n 2}$ & Mode $_{n m}$ \\
\hline
\end{tabular}

IV. THE DESIGN PROCESS OF CONSTRUCTION TRANSACTION MODES

According to the general principals of engineering design, researchers show the design process of construction project transaction mode in Fig. 1.

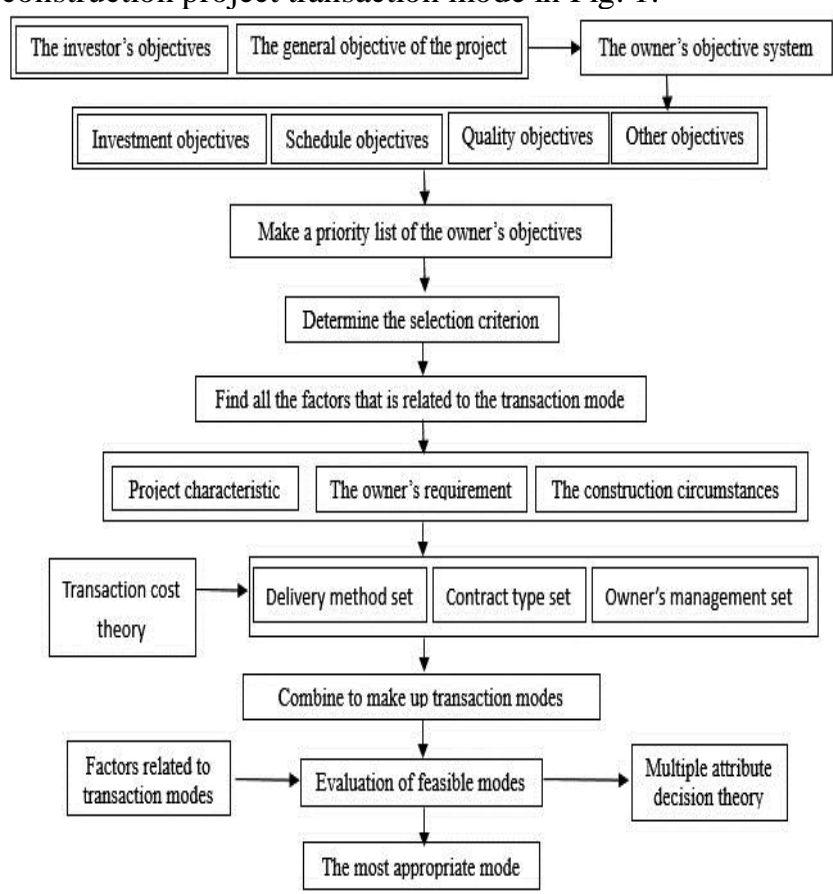

Figure 1. The design process of transaction mode 
The specific design process can be described as follows: Step 1: Establish the owner's objective system based on the investor's objectives and the general objective of the project. Generally speaking the owner's objective system can be divided into investment objectives, schedule objectives, quality objectives and other objectives.

Step 2: Make a priority list of the owner's objectives and determine the selection criterion. The transaction criterion usually include how to invite tenders (open tender or invited tender), how to evaluate the bid and so on.

Step 3: Analyze all the factors that is related to the transaction mode. Figure out all the factors that may influence the transaction mode, which usually consist of project characteristic, the owner's requirement and the construction circumstances. Then analyze each factor according to the project.

Step 4: Build the feasible transaction modes set. Based on the transaction cost theory, build the delivery methods set, contact types set and owner's management set. Then combine them to get feasible transaction modes set.

Step 5: According to the multiple attribute theory and the factors related to the transaction modes, evaluate the transaction modes in the set to figure out the most appropriate one.

\section{A. The selection process of delivery methods}

The delivery method determines the responsibility and the relationship between the project participants and the order of each procedure in the project. For most of the project owners, there exist many feasible delivery methods and each method has its own feature. In order to select them more conveniently, this paper has built an alternative delivery methods matrix based on the evaluation method of bidding and the relationship between design and construction, which is shown in Table 2.

Table 2 the alternative delivery method matrix

\begin{tabular}{|c|c|c|}
\hline $\begin{array}{c}\text { The evaluation } \\
\text { method of bidding }\end{array}$ & $\begin{array}{c}\text { The relationship between design } \\
\text { and construction }\end{array}$ \\
\cline { 2 - 3 } & separated & lapped \\
\hline $\begin{array}{c}\text { The lowest price } \\
\text { bid evaluation }\end{array}$ & DBB,GC & DB \\
\hline $\begin{array}{c}\text { Comprehensive } \\
\text { evaluation method }\end{array}$ & $\begin{array}{c}\text { DBB,GC, } \\
\text { CM-at risk }\end{array}$ & $\begin{array}{c}\text { DB, EPC, } \\
\text { Turn-Key }\end{array}$ \\
\hline $\begin{array}{c}\text { Competitive } \\
\text { evaluation method }\end{array}$ & CM-at risk & $\begin{array}{c}\text { EPC, Turn-Key, } \\
\text { PMC }\end{array}$ \\
\hline
\end{tabular}

Based on the characteristics of construction project and the related design factors, researchers build the feasible delivery method set through four steps, which is shown as followings:

Step 1: Build the alternative delivery method matrix. A project usually has more than one feasible delivery method. The matrix can help the owner to find all the feasible ways so as to make better choices. Researchers can build the matrix like Table 2

Step 2: Delete the infeasible delivery method based on the schedule objectives. The owner should consider the following questions to determine whether the schedule is tight or not according to the total objective of the project. Question 1: Is the relationship between the design and construction lapped? If the answer is yes, the owner should select the delivery method from the lapped ones. Then question 2: Could the project start constructing after primary design? If the answer is no, the owner could only select from the EPC, Turn-Key and PMC. Therefore researchers can delete the ones of grey background in Table 2.

Step 3: Delete some delivery methods from the matrix based on the complexity of the project.

1) The definition of the project range. Before selecting the delivery method the owner should know whether the project range is clear or not. If it has not been decided clearly, the owner should answer the question whether it is difficult to define the project range. If the answer is yes, the owner should select the delivery method that is corresponded with the comprehensive evaluation method and take the contractor's credit, qualifications into consideration.

2) The contractors' advice. To complex projects, the early joining of the contractor will be beneficial to improve the practicability of the design and reduce the disputes in the construction period. Therefore the owner should answer the question whether the design process needs the contractor's joining. If the answer is yes, the owner should select the delivery method that is beneficial to the contractor's joining, such as CM-at risk, DB, PMC and so on.

3) The changing possibility in the construction process. For the projects that have high possibility of changing, the owner should pay attention to the contractor's credit and qualifications. The owner needs to answer the question whether there is a high possibility of changing in the construction. If the answer is yes, the owner should select the delivery method that is correspondent to the comprehensive evaluation method.

Step 4: Delete the infeasible delivery methods based on the owner's management ability.

1) The owner should consider whether he has the ability to examine the design files. If the answer is no, the owner should select ones that are convenient for external forces to examine them, such as CM-at risk.

2) The owner should also consider whether he has the ability to manage several master contractors at the same time. If the answer is no, the owner can select ones like $\mathrm{DB}$ or EPC or use the eternal forces to manage the project. Step 5: Delete the infeasible delivery methods based on the local policies and regulations.

Generally speaking, the governments have some mandatory provisions about construction projects. Thus the owner should consider the question whether the alternative methods are legal. The illegal methods should be out of consideration.

Through the above steps, the remaining delivery methods in the matrix are feasible ones.

\section{B. The selection process of contract types}

The contract type is related to the depth of design and fuzziness of the project. When the design depth is low, the fuzziness of the project will be correspondently higher. Thus researchers should use cost reimbursable contract. With the design developing deeper, the fuzziness of the project will decline. The lump sum contract will be better. The specific analysis is as follows:

1) When the project is in the construction drawing design stage and the construction organization design is relatively complete, the lump sum contract is more suitable. 
2) When the project is in the primary design stage, the design index or the engineering quantity is not certain, the unit price contract is more correct.

3) When the project is in the concept design stage, it is suitable to use the cost reimbursable contract. Besides for those projects whose delivery methods are PMC, EPC or Turn-Key, the target contract is more correct. Because the owner would be able to get a reliable investment cost and furtherly control the project cost.

\section{The selection process of owner's management}

The owner's management is influenced by the project's economic attribute, the owner's management ability and the project's complexity. Researchers can select it according to the flow chart in Fig. 2.

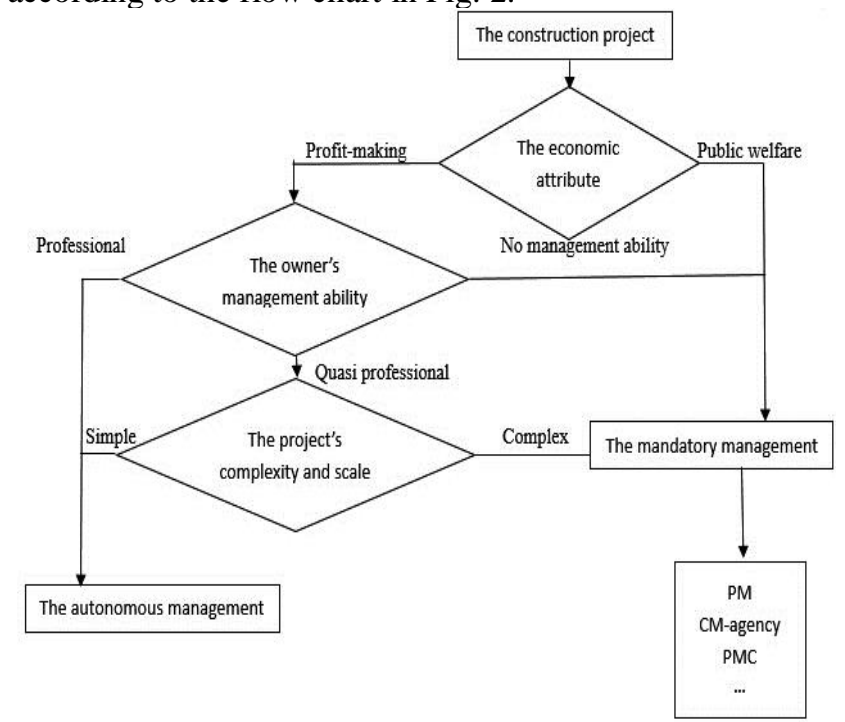

Figure 2. The selection flow chart of the owner's management

The specific analysis of the flow chart is as follows:

Step 1: Figure out the project's attribute. If it is public welfare, it would be suitable to use mandatory management. If it is profit-making, go to the next step.

Step 2: Assess the owner's management ability. If the owner have professional management ability, the autonomous management would be better. If the owner have no management ability, it is correct to use mandatory management. If it is quasi professional, go to the next step.

Step 3: Combining the complexity of the project and own management ability, the owner should consider the question whether he needs professional service to assist. If the answer is yes, then use mandatory management. If the answer is yes, then use autonomous management.

\section{The construction project transaction modes set}

After selecting the delivery methods, contract type and the owner's management, combine them to obtain feasible transaction modes, which are shown in Fig. 3.

\section{THE ENGINEERING EXAMPLE}

\section{A. The introduction of the project}

A water diversion project mainly includes two parts that is water diversion and control pollution. The diversion part consists of reconstructing the canal and improving the existing project of Sanyang River, Jinbao Channel and Xuhong River, which will newly build 14 pump stations and reconstruct 4 pump stations. Started in November 2002 , the static investment of the project is 13.8 billion including 9.2 billion in water diversion and 4.6 billion in controlling pollution. In the diversion part, the first group of project includes Sanyang River Station, Tonghe Station, Baoying Station, Jiangdu Station reconstruction, four stations in Huaian, three stations in Huaiyin, Liushan Station, Jietai Station, Linjiaba Station and Luoma Lake water resources control. The planned investment of this group is 2.5 billion. Until the end of June 2008, this group of projects has already been completed 95\%. In the second half of 2009, five design unit projects like Siyang Station will be started. The other stations will also be on construction in succession. In the pollution control part, by the end of June 2009, the Jiangsu part has completed 90 items, which has exceeded $90 \%$ of the planned investment.

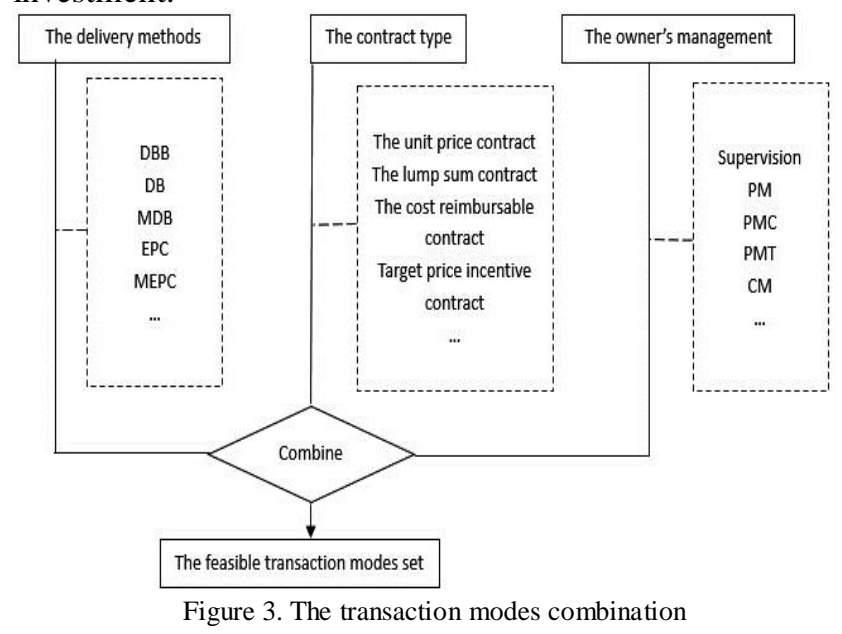

B. The delivery methods, contrct types and the owner's management

According to the project's characteristic and the owner's management ability, researchers build the sets of delivery methods, contract types and the owner's management.

(1) The feasible delivery methods

1) The delivery method of river channel projects. The river channel projects are distributed along the river and probably in different administrative areas; the related technology is simple, but the construction circumstances, especially the house demolition and coordinating the relationships, are complicated. Under the influence of traditional delivery method there are few CM contractors could coordinate the relationship in the construction process. Therefore researchers should use DBB to make the design and the construction separated delivered.

2) The delivery method of the pump station. The pump station projects are rather concentrated and the external relationship coordination is simple. However the inner relationship coordination is complicated. In this case, DB, EPC or CM-at risk has more advantage than other methods. Considering the fact that the DB or EPC contractors that have the general contract ability in the construction market are lacked, it is impossible to use this kind of method in all the projects of this group. Hence researchers have to use DBB (general construction contractor) as well. Besides the owner is experienced in purchasing equipment and the civil engineering is closely 
related to equipment installation. It would be distracting to contract by item. Therefore researchers could use DB and furtherly divide it into two kinds: DB (after primary design) and DB (after contract design). In conclusion there are three delivery methods: DB (after primary design), DB (after contract design) and DBB (general construction contractor).

\section{(2) The feasible contractor types}

The river channel project and the pump station project are all constructed after primary design; there still exists some uncertain factors and the schedule is always in 1 or 2 years. Thus the unit price contractor is the most appropriate.

\section{(3) The feasible owner's management}

1) Owner's management in the river channel project. Considering the fact that the owner's management ability is limited and the construction circumstance is complicated, researchers use construction agent/PM + supervision. Hence the owner's management style is "the owner's representatives + the construction agent+ the supervision". The practical experience has already proven it reasonable.

2) Owner's management in the pump station project. Compared with the channel project, the construction circumstances in the pump station is simple. The owner could use "the owner + supervision (leading)" or "the owner + supervision (auxiliary) to manage the project. The practical experience of the first group of projects proves them feasible.

In total researchers can get the feasible ways of river channel project and the pump station project. The river channel project only have one kind of delivery method, contract type and owner's management; the pump station projects have three delivery methods, one contract type and two kinds of owner's management.

\section{The set of feasible transaction modes}

Combined with the feasible delivery methods, contract types and the owner's management, researchers can get the set of feasible transaction modes.

\section{(1) The set of river channel project}

There is only one transaction mode in the river channel project, which is " $\mathrm{DBB}+$ the unit price contract+ the owner's representatives + the construction agent + the supervision".

(2) The set of the pump station project. Through combination researchers get 6 feasible transaction modes, which is shown in Table 3

Table 3 the feasible transaction modes in pump station project

\begin{tabular}{|c|c|c|}
\hline & $\begin{array}{c}\text { Owner + } \\
\text { Supervision } \\
\text { (auxiliary) }\end{array}$ & $\begin{array}{c}\text { Owner+ } \\
\text { Supervision( } \\
\text { leading) }\end{array}$ \\
\hline $\begin{array}{c}\text { DB( after contract } \\
\text { design) }\end{array}$ & Mode1 & Mode2 \\
\hline $\begin{array}{c}\text { DB( after primary } \\
\text { design) }\end{array}$ & Mode3 & Mode4 \\
\hline $\begin{array}{c}\text { DBB(general } \\
\text { construction } \\
\text { contract) }\end{array}$ & Mode5 & Mode6 \\
\hline
\end{tabular}

(3) The compatibility analysis in the transaction mode of pump station project

Through combination researchers have get the set of feasible transaction mode in Table 3 . In the 6 modes, there are no principle conflicts. However considering that the owner's management ability is limited, it is impossible to apply Mode1, Mode3 or Mode5 to all the projects. Besides the DB contractor is lacked in the construction market, so researchers couldn't use DB in all the projects of one group.

\section{CONCLUSIONS}

This paper has built the transaction mode design process and analyzed the related key problems. The complexity of the project, the fuzziness of the construction and the owner's management ability are vital factors in the design. Researchers have proposed the selection process of delivery methods, contract types and the owner's management according to the analysis results. In this paper, quantitative analysis are provided for the owner to design the transaction modes based on the feasible sets and the combination of delivery methods, contract types and the owner's management. The application in the example has achieved the aim of reducing the feasible transaction modes while making decisions, which has proven the effectiveness of this design process.

\section{REFERENCES}

[1] CHEN Yongqiang, JIAO Junshuang. Influence of project delivery system and payment method on project cost performance $[\mathrm{J}]$. Journal of Tongii University (Natural Science), 2011, 39(09):1407-1412.

[2] CHEN Yongqiang, ZHANG Wen. Comparison of project production efficiency between DBB and DB delivery system on production frontier [J].Journal of Tongji University (Natural Science), 2013,41(02):309-316.

[3] LIU Xun, WANG Zhuofu. Research on project delivery systems decision method based on FOWGA operator[J].Journal of Xi' an University of Architecture \& Technology(Natural Science Edition), 2014,46(01):56-63,70.

[4] WANG Zhuofu, YANG Gaosheng, HONG Weimin. Construction Engineering Trade Theory and trading patterns [M].Beijing: Hydraulic and Hydroelectricity Press, 2010.

[5] WANG Zhuofu, CHEN Liang, CHEN Shu. Economic analysis of owner's management approach in project transaction [J].Soft Science, 2008, 22(01): 9-11.

[6] Konchar M, Sanvido V. Comparison of US project delivery systems [J]. Journal of Construction Engineering and Management, 1998, 124(6):435-444.

[7] Kent D, Becerik-Gerber B. Understanding Construction Industry Experience and Attitudes toward Integrated Project Delivery [J]. Journal of Construction Engineering and Management, 2010, 136(8):815-825.

[8] Swarup L, Korkmaz S, Riley D. Project Delivery Metrics for Sustainable, High-Performance Buildings [J]. Journal of Construction Engineering and Management, 2011, 137(12):10431051.

[9] Mollaoglu-Korkmaz S, Swarup L, Riley D. Delivering Sustainable, High-Performance Buildings: Influence of Project Delivery Methods on Integration and Project Outcomes [J]. Journal of Management in Engineering, 2013, 29(1):71-78.

[10] Al-Subhi Al-HarbiKM. Sharing fractions in cost-plus-incentivefee contracts $[\mathrm{J}]$. International Journal of Project Management, 1998, 16(2):73-80.

[11] Zaghloul R, Hartman F. Construction contracts: the cost of mistrust [J]. International Journal of Project Management 2003, 21(6):419-424.

[12] Gordon CM. Choosing Appropriate Construction Contracting Method [J]. Journal of Construction Engineering and Management, 1994, 120(1):196-210. 
[13] Turner JR, Simister SJ. Project contract management and a theory of organization $[\mathrm{J}]$. International Journal of Project Management, 2001, 19(8):457-464.

[14] LI Huimin, WANG Zhuofu.SpectrumAnalysis and Design Model for Construction Project Delivery System [J]. Science \& Technology Progress and Policy, 2009, 26(21):91-94.

[15] YANG Gaosheng, WANG Min, WANG Zhuofu. Design analysis of project delivery mode [J].Construction Economy, 2007(07):109-111, 37.
[16] Touran A, Gransberg DD, Molenaar KR, Ghavamifar K. Selection of Project Delivery Method in Transit: Drivers and Objectives [J] Journal of Management in Engineering, 2011, 27(1):21-27.

[17] Touran A, Molenaar KR, Gransberg DD, Ghavamifar K. Decision Support System for Selection of Project Delivery Method in Transit[J]. Transportation Research Record, 2009(2111):148-157. 